\title{
DOCUMENTOS
}

\section{Una Carta Inédita de José Enrique Rodó}

\author{
Rodó y la Literatura Chilena
}

En el año 1900, el entonces joven pensador uruguayo, José Enrique Rodó inauguró el nuevo siglo con los conceptos expuestos en Ariel, libro que le convirtió en el mentor continental de toda una generación americana. Durante la primera década del siglo, este texto y su autor alcanzaron tal fama que cuando se publicó Motivos de Proteo, en 1909, Rodó ya era el maestro acatado de los jóvenes idealistas que seguían sus pasos desde diversos rincones del continente.

El pensamiento rodoniano tuvó una resonancia particular en Chile; en 1910, Rodó, tras haber manifestado sus ideas en los Congresos Internacionales de Estudiantes Americanos, viajó a la república trasandina como integrante de la delegación uruguaya a las fiestas conmemorativas del Centenario de la Independencia de Chile. Su presencia allí conmovió a toda la intelectualidad chilena, y en forma especial a dos jóvenes: Pedro Prado y Ernesto A. Guzmán.

Los dos poetas chilenos en esta época habían decidido fundar una revista no exclusivamente literaria sino que luchara también por poner en circulación estudios serios sobre los diversos problemas intelectuales del momento. Pedro Prado acababa de regresar de un Congreso de Estudiantes efectuado en Buenos Aires como parte del programa de festejos del Centenario de la nación argentina. Efectivamente, el ideario pregonado por Rodó había penetrado en el ámbito americano. En noviembre de 1910, dos meses después de la visita de Rodó a Santiago de Chile, apa- 
reció el primer número de la Revista Contemporánea fundada por Prado y Guzmán.

Como en la antigua Revista Nacional de Literatura y Ciencias Sociales dirigida por Rodó, se incluyeron en la Revista Contemparánea ("Publicación mensual de literatura, ciencias, artes, etc."), ensayos artículos críticos y páginas de literatura que revelaban la nueva tendencia intelertual, mostrando la huella del idealismo rodoniano y el consiguiente propósito editorial de promover una renovación espiritual en sus lectores.

Buen indicio de la orientación renovadora de la revista se da en las contribuciones llegadas del extranjero. Entre muchos otros nombres signiticativos se destacan los de Manuel Machado, Miguel de Unamuno, Santiago Rusiñol, Guillermo Valencia, Enrique Banchs, Carlos Vaz Ferreira y el mismo Rodó. Fuera de los fundadores el chileno que más rigurosamente reflejaba la trascendencia del pensamiento rodoniano era el filósofo Enrique Molina, que publicó en la revista una serie de ensayos relativos a la crisis de la moral. ${ }^{1}$

Cabría señalar aquí que la admiración de los chilenos hacia la figura y el pensamiento de Rodó no terminó con la Revista Contemporánea (sólo logró publicar cinco entregas). Años más tarde, en pleno apogeo de la sociedad artística de Los Diez, ${ }^{2}$ al enterarse de la muerte de Rodó, se publicó un número especial de la revista Los Diez en homenaje al malogrado maestro. La edición, de junio de 1917, contenía una selección de los Motivos de Proteo representada por los ensayos de Pedro Prado, Ernesto A. Guzmán, Armando Donoso y Luis David Cruz Ocampo. Interesa saber que los ensayos de los chilenos fueron incluidos también en el número extraordinario que le dedicó la revista argentina Nosotros en 1917. Así, José Enrique Rodó, en su muerte tanto como en su vida, logró promover una actitud espiritual de solidaridad internacional que no solamente era en homenaje a su memoria, sino que expresaba también la voluntad de difundir las ideas vitales del gran idealista del novecientos.

En 1911 el Maestro, halagado por el esfuerzo editorial de Prado y Guzmán, les dirigió una amena carta en que esbozó sus ideas fundamen-

1 "Las crisis de la moral," I, 1 (noviembre 1910), 2-13; I, 2 (diciembre 1910), 118-124; "La moral como ciencia y como arte," I, 4 (febrero 1911), 263-278.

z La hermandad artística de Los Diez floreció hacia 1916. La decena de gran envergadura en el medio chileno de entonces, representó una síntesis fraterna de arte, música y literatura. Bajo la dirección de Pedro Prado se publicó la revista Los Diez que alternaba con ediciones de libros. Véase nuestro estudio "Recapitulación de la historia de Los Diez," Atenea, CLXVII, 420 (abril-junio $1968), 111-127$. 
tales sobre la orientación necesaria para una revista de índole intelectual, y en particular sobre la nueva empresa de la Revista Contemporánea. En este documento relevante, que a continuación se publica, ${ }^{2}$ pueden notarse varias constantes del pensamiento de Rodó: su cautela frente a la novedad; su exigencia de unidad orgánica; su reconocimiento de "las peculiares condiciones de estos pueblos de América", actitudes todas que convergen en su propio concepto espiritual del continente hispánico. De tal modo, en esta carta Rodó sintetiza su pensamiento y lo aplica al caso concreto de la nueva revista, dejando constancia de los requisitos indispensables de toda empresa de orden intelectual.

The University of Chicago

ReNÉ de Costa

La Carta de Rodó

Señores

don Pedro Prado y D. Ernesto A. Guzmán

de la Revista Contemporánea de Chile.

No hago uso de un lugar común impuesto por la cortesía literaria, si afirmo que me ha interesado de veras la revista de Uds. y que deseo vivamente su prosperidad.

En rigor, nunca una afirmación semejante dejará de estar justificada y de merecer que haya en ella un sentimiento sincero, tratándose de revistas hispanoamericanas de índole desinteresadamente intelectual; a menos que el desacierto de la dirección, la trivialidad del contenido, la perversidad del gusto, sean tales como para graduarlas de enteramente vanas, o de perniciosas: juicio que pocas veces puede darse con seguridad, porque a las revistas es aplicable, con más conveniencia que a los libros, aquello de que "no hay libro absolutamente malo". La revista es, por naturaleza, obra de muchos, y obra que persiste y se desenvuelve en el tiempo; y habría que suponer, en quien la dirija, una rara infalibilidad negativa, una inverosimil fatalidad de mal gusto y de mal tino, para aceptar que, ni aún por excepción, logre tener cabida, entre lo malo, alguna cosa buena.

3 Esta carta inédita permanecia en el archivo de Pedro Prado custodiado por la hija del poeta, doña Inés Prado de Zegers. En la edición que Los Diez publicó en homenaje a Rodó se reprodujo tan solo un fragmento ("Autógrafo de Rodó"). 
Tardará en aparecer lo bueno, si se quiere, pero aparecerá; y entonces el mérito de revelarlo y difundirlo será bastante para redimir a la revista de sus culpas. Yo, por lo menos, pienso de esta manera, y creo -completando mi pensamiento - que, para juzgar de revistas literarias hispanoamericanas, con tan precario ambiente y tan dudosas recompensas, es de plena justicia adoptar un criterio parecido al que el vulgar proloquio aplica al "caballo regalado".

Pero esta lenidad y esta condescendencia se convierte en franco aplauso, en satisfacción, no ya relativa, sino absoluta, y aun diré en cierto sentimiento de gratitud, cuando la revista, por su seriedad y su mérito se sustrae a la aplicación de tales filosofías y realza el valor que moralmente tiene el acto desinteresado de fundarla y sostenerla, con la calidad intelectual que hace de ella un positivo, un eficaz instrumento de cultura. Tal es el caso de la Revista Contemporáned, y tal el motivo de que las palabras con que empiezo esta carta tengan en ella un valor no descontado por ningún género de reservas mentales.

Desde luego, me agrada en las revistas una condición que reconozco en la de Uds. Hoy abundan y prevalecen aquellas cuyo carácter; o mejor, cuya ausencia de carácter, no las distingue de las meras compilaciones. No hay en ellas una orientación fundamental, una unidad que se levanta sobre la variedad, una fisonomía, un sello propio. Yo no concibo así la revista ideal. Hospitalidad, libertad, amplitud, hasta el extremo que se quiera; pero, por encima de esas cualidades, imprímase cierto carácter de conjunto que manifieste cómo toda aquella varia labor va enderezada, por la mano que la dirige y concierta, a una determinada finalidad, a una determinada concepción del arte o de la vida. No excluir a nadie cuya palabra merezca y deba atenderse; no negar hospitalidad ni aun para la contradicción de los propósitos y afectos que en la revista predominen, son franquicias perfectamente conciliables con la exigencia de que resalte en sus páginas una personalidad bien diferenciada. Si yo fundase una revista, había de procurar, por medio de ella, "arrimar el ascua a mi sardina", es decir a las ideas que creo verdaderas y justas, y por tanto, dignas de propagarse. Como me precio más que de ninguna otra condición, de ser un espíritu amplio, y aspiro a entenderlo y comprenderlo todo, tendría abiertas las puertas de la casa pata quien quiera que trajese por credencial una idea interesante o una forma bella; pero esto no me impediría hacer de modo que se conociera que, para el efecto del conjunto, era yo el que dirigía y ordenaba las cosas.

En la Revista Contemporánea percibo ese carácter de personalidad. Se ve, desde el primer momento, que no es un estímulo vanidoso, de los 
que satisfase la publicidad con sus vulgares halagos, el que ha inspirado y preside a la obra, sino la natural tendencia de expansión de un ideal de cultura y de orientación literaria, que arraiga hondo en el espíritu de quienes lo predican.

La oportunidad es buena, por estos mundos, para que revistas así aparezcan y se propaguen. Los que tienen ideas, los que algo han pensado sobre las cuestiones de fundamental interés social, espiritual, artístico, en su adaptación a las peculiares condiciones de estos pueblos de América; los que sienten la necesidad de propender a que se determine y revele un alma hispanoamericana, para animar una civilización que algún día podamos llamar propia, y que no se logrará, seguramente con sólo el desenvolvimiento de fuerza material y de riqueza — deben hablar de modo que se les oiga con la asidua atención que una revista solicita y mantiene. Este es un momento de renovación, e importa apresurarla. Todo anuncia que nuestra literatura tiende a ser energía social y obra de pensamiento. Los versos celestes, morados, rojos y amarillos, no interesan ya a nadie; y bajo la máscara, rota en pedazos, de un arte de vanidad y de remedo, quiere ya manifestarse una fisonomía real y viva, hecha de carne y de alma.

Grato el pedido de Uds, y deseándoles en su empresa todo bien merecido, les saluda afectuosamente.

Montevideo, 10. de abril de 1911

Firmado:

José EnRIQue Rodó 
